\title{
Habitat selection by green turtles in a spatially heterogeneous benthic landscape in Dry Tortugas National Park, Florida
}

\author{
Ikuko Fujisaki ${ }^{1, *}$, Kristen M. Hart ${ }^{2}$, Autumn R. Sartain-Iverson ${ }^{3}$ \\ ${ }^{1}$ University of Florida, Ft. Lauderdale Research and Education Center, Davie, FL 33314, USA \\ ${ }^{2}$ US Geological Survey, Wetland and Aquatic Research Center, Davie, FL 33314, USA \\ ${ }^{3}$ Cherokee Nation Technologies, contracted to US Geological Survey, Wetland and Aquatic Research Center, Davie, \\ FL 33314, USA
}

\begin{abstract}
We examined habitat selection by green turtles Chelonia mydas at Dry Tortugas National Park, Florida, USA. We tracked 15 turtles ( 6 females and 9 males) using platform transmitter terminals (PTTs); 13 of these turtles were equipped with additional acoustic transmitters. Location data by PTTs comprised periods of 40 to $226 \mathrm{~d}$ in varying months from 2009 to 2012 . Core areas were concentrated in shallow water (mean bathymetry depth of $7.7 \mathrm{~m}$ ) with a comparably dense coverage of seagrass; however, the utilization distribution overlap index indicated a low degree of habitat sharing. The probability of detecting a turtle on an acoustic receiver was inversely associated with the distance from the receiver to turtle capture sites and was lower in shallower water. The estimated daily detection probability of a single turtle at a given acoustic station throughout the acoustic array was small ( $<0.1$ in any year), and that of multiple turtle detections was even smaller. However, the conditional probability of multiple turtle detections, given at least one turtle detection at a receiver, was much higher despite the small number of tagged turtles in each year ( $\mathrm{n}=1$ to 5 ). Also, multiple detections of different turtles at a receiver frequently occurred within a few minutes (40\%, or 164 of 415, occurred within 1 min). Our numerical estimates of core area overlap, co-occupancy probabilities, and habitat characterization for green turtles could be used to guide conservation of the area to sustain the population of this species.
\end{abstract}

KEY WORDS: Acoustic telemetry $\cdot$ Co-occupancy $\cdot$ Habitat selection $\cdot$ Satellite telemetry

\section{INTRODUCTION}

Habitat selection in response to spatial heterogeneity is a common theme in landscape, population, and evolutionary ecology, and is important for habitat conservation (Morris 2003a,b). Both abiotic and biotic factors can dictate habitat selection; the physical environment is considered a primary factor influencing resource availability, but species' fitness is also dependent on population density and interactions, such as competition (Rosenzweig 1991). Animals may use information such as proximity to conspecifics in both positive (attraction) and negative

\footnotetext{
*Corresponding author: ikuko@ufl.edu
}

(avoidance) ways (Dall et al. 2005), and understanding how individuals position themselves relative to others could improve our ability to conserve wildlife populations (Ward \& Schlossberg 2004).

Most conspecific habitat selection studies have predominantly centered on terrestrial species (e.g. birds by Ward \& Schlossberg 2004; reptiles by Stamps 1991), while a comparably small number of studies exist in the marine realm (e.g. turtles by Schofield et al. 2006, 2007; fish by Lecchini et al. 2007). This is likely due to the challenges involved in observing individuals during experiments. Experimental manipulation is particularly difficult for highly

๑ The authors 2016. Open Access under Creative Commons by Attribution Licence. Use, distribution and reproduction are unrestricted. Authors and original publication must be credited.

Publisher: Inter-Research · www.int-res.com 
mobile and large-bodied marine vertebrates, such as sea turtles. Sea turtles play key roles in coastal and coral reef ecosystem function, with direct links between green turtles Chelonia mydas and seagrass productivity through herbivory (Thayer et al. 1984, Moran \& Bjorndal 2005) and indirect links for all species of sea turtles to nutrient cycling through nesting activities on beaches (Bouchard \& Bjorndal 2000, Bjorndal \& Jackson 2003).

There is a small body of literature that has examined group activity, social structure, or conspecific interactions, but sea turtles have generally been considered solitary animals. Lanyon et al. (1989) described that green turtles do not form organized groups; during courtship they use visual and chemical cues to find each other (Ernst et al. 1994, Spotila 2004). Bjorndal (1980) reported an absence of aggressive behavior and an indication of a hierarchy for some green turtle populations, whereas Schofield et al. (2007) observed aggressive behavior between female loggerheads Caretta caretta during courtship and inter-nesting periods. During foraging periods, habitat selection is influenced by environmental factors such as resource availability and water depth (Seminoff et al. 2002, Senko et al. 2010), but little is known about the effect of conspecific proximity. Previous satellite telemetry results have shown green turtle core areas in close proximity and sometimes overlapping (Seminoff et al. 2002, Hart et al. 2013). However, potentially large location errors in satellite data make it uncertain whether these turtles use locations concurrently on a smaller scale. Studies on loggerheads have shown consistent use of the same foraging site over successive years (Broderick et al. 2007, Schofield et al. 2010) suggesting that some sea turtles may establish distinct territories (Hart et al. 2015). Similarly, an acoustic telemetry study in Low Isles, Australia, indicated that green turtles had different core areas within the reef complex, which implies individuals adopted unique optimal resourceuse patterns (Hazel et al. 2013). However, GPS tracking of pre- and internesting female loggerheads indicated that turtles were found in closer proximity than expected at random (Schofield et al. 2009). Here, by combining satellite and acoustic telemetry data, we investigate in-water habitat selection of subadult and adult green turtles in a spatially heterogeneous neritic zone.

Green turtles can migrate up to 1000 s of $\mathrm{km}$ between foraging and nesting sites (Mortimer \& Portier 1989, Plotkin 2003), but satellite tracking has shown that not all green turtle populations migrate long distances (Hart et al. 2013). Short distances (2 km) post- nesting migrations, indicating close proximity between nesting and foraging sites, have also been observed (Limpus et al. 1992). Studies using flipper tags and satellite telemetry have shown multi-year use of foraging grounds by green turtles, suggesting high long-term site fidelity to foraging areas (Limpus et al. 1992, Broderick et al. 2007). Adult green turtles are herbivorous and primarily consume seagrass and algae, so their foraging grounds are frequently in seagrass-dominated ecosystems (Bjorndal 1985, 1997, Garnett et al. 1985, Bolten 2003). However, green turtle diet can vary by foraging ground (Bjorndal 1985, 1997), life stage (Bolten 2003), and the availability of food sources (Garnett et al. 1985). Recent studies using stable isotope analysis and animalborne videos suggested more variation in green turtle diet than previously thought (Vander Zanden et al. 2010, Burkholder et al. 2011).

Combining satellite telemetry and passive acoustic telemetry at fixed locations, we quantified the likelihood of (1) core area overlap and (2) co-occupancy by multiple turtles. We defined co-occupancy as simultaneous detections of multiple turtles by the same receiver in a unit of time. We also (3) tested the effect environmental factors, including bathymetry, benthic type, and proximity to capture site have on habitat selection, and (4) examined daily and seasonal patterns in co-occupancy.

\section{MATERIALS AND METHODS}

\section{Study species}

Our study species is the Endangered green turtle Chelonia mydas (Hilton-Taylor 2000). Distributed globally in tropical and subtropical waters (Hirth 1997), populations of green turtles have declined worldwide due to various anthropogenic causes (Groombridge \& Luxmoore 1989, Limpus 1995).The IUCN (Hilton-Taylor 2000) highlights the need to understand the foraging and movement ecology of this species for conservation planning.

\section{Study area}

The study was conducted within Dry Tortugas National Park (DRTO), the southwesternmost point of Florida, USA. DRTO is within Florida Keys National Marine Sanctuary (FKNMS), one of 14 marine protected areas of the National Marine Sanctuary System. The area is also within the Northwest At- 


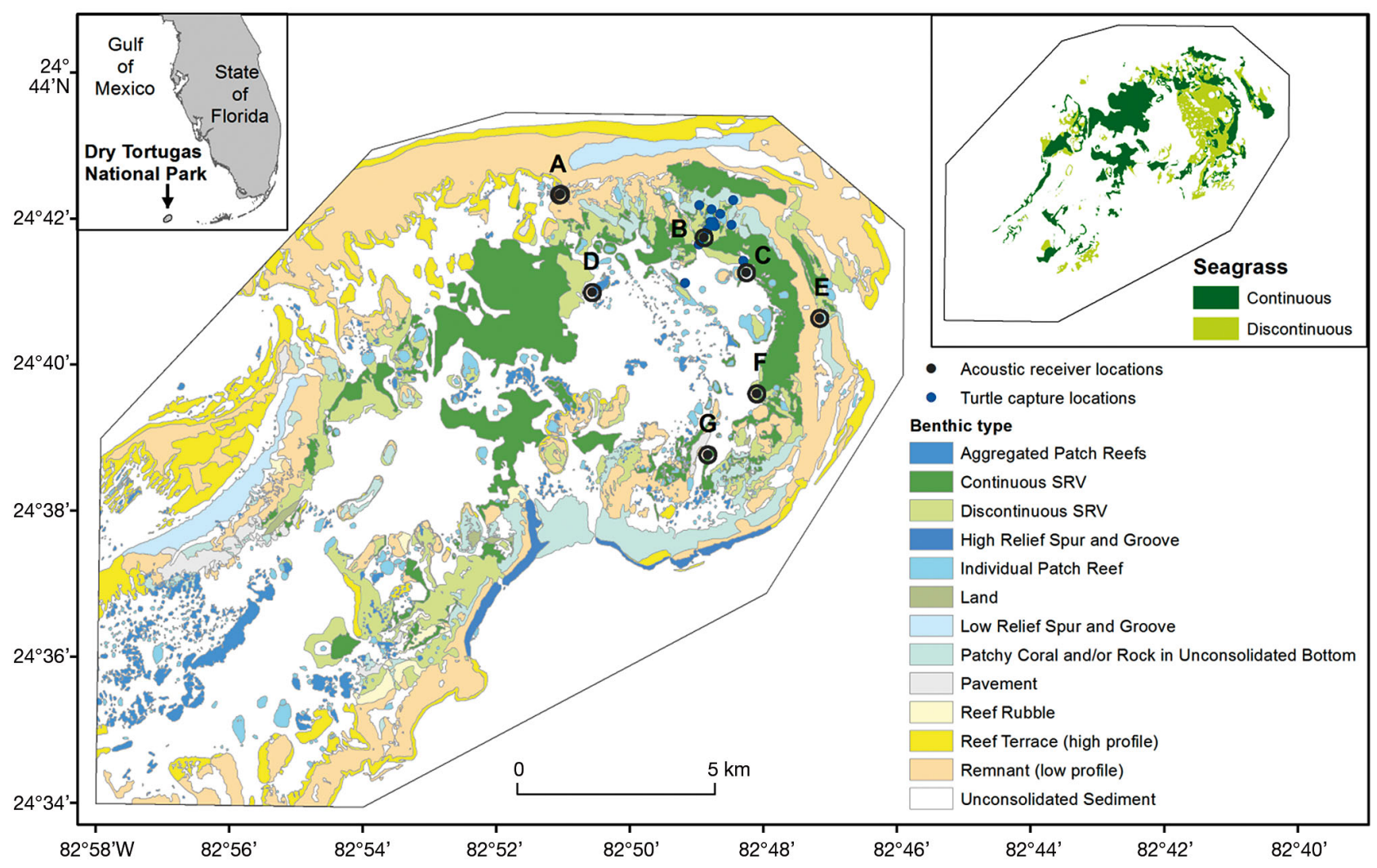

Fig. 1. Dry Tortugas National Park (DRTO) with benthic type, turtle capture locations (n = 15), and locations of acoustic stations (receiver locations A-G) shown with $200 \mathrm{~m}$ buffer (the approximate maximum distance to $100 \%$ detection probability; Kessel et al. 2014) from the center (outer circle). Inset boxes show the location of DRTO in the State of Florida, USA (top left) and seagrass cover type in DRTO (top right). SRV: submerged rooted vascular plants

lantic Regional Management Unit (RMU), one of 17 defined population RMUs for green turtles (Wallace et al. 2010). The area is characterized by a subtropical climate and a variety of benthic habitat types (Fig. 1). Whereas green turtle nesting activities occur in DRTO (Reardon 2000), possible year-round residency of some adult females seen nesting locally suggests this may also be their foraging site (Hart et al. 2013). Within DRTO, an array of acoustic receivers (Vemco VR2 and VR2W) was maintained to monitor marine life. This study uses data from 7 active receivers deployed (1.4-7.6 km apart) in water depth $4.8-12.8 \mathrm{~m}$ in the northwest part of DRTO (Fig. 1). In this area underwater visibility generally ranges from 3 to $30 \mathrm{~m}$ and there is some degree of human disturbance such as boating, fishing, and anchoring.

\section{Deployment of satellite and acoustic tags}

Satellite telemetry is an established method to delineate habitats of free-ranging animals (Hays et al. 1991, Godley et al. 2008, Hart \& Hyrenbach 2009).
Arrays of acoustic receivers at predetermined locations, however, can provide information on the use of specific locations by individuals (How \& de Lestang 2012). We tracked green turtles by satellite telemetry and recorded detections at acoustic receivers deployed at fixed locations between 2009 and 2012. Because of the composition of the study site and logistics, we concentrated our capturing efforts in the northern portion of DRTO where we can reliably work to capture green turtles (Fig. 1; K. M. Hart pers. obs.).

Following the established protocols (NMFS SEFSC 2008), we caught turtles using the rodeo or turtlejumping technique (diving from a boat to capture turtles; Ehrhart \& Ogren 1999). Once we brought a turtle aboard the boat, we took standard measurements, including curved (CCL) and straight (SCL) carapace lengths from the anterior notch to the last posterior marginal scute, and took photographs to document carapace and skin anomalies. Based on external assessment of animal size and tail size, we categorized them into subadult-sized (65-90 cm SCL; Bresette et al. 2010) and adult-sized (>90 cm SCL) 
females or males; male turtles of which we took tail measurements $(n=5)$ had cloaca-tip lengths $\geq 5.5 \mathrm{~cm}$. We tagged each animal with a passive integrated transponder (PIT) in the right shoulder and affixed an individually numbered flipper tag to each front flipper.

We fitted a Wildlife Computers SPOT5 platform terminal transmitter (PTT) to each turtle; each tag $(2.5 x A A$ model, $71 \mathrm{~mm}$ long $\times 54 \mathrm{~mm}$ wide $\times 24 \mathrm{~mm}$ high) had a saltwater switch. Tags had an output of $0.5 \mathrm{~W}$ and a mass of $115 \mathrm{~g}$ in air. Prior to transmitter application with either Power-Fast ${ }^{\mathrm{TM}}$ or SuperBond ${ }^{\mathrm{TM}}$ 2-part cool-setting marine epoxies, we removed epibionts (e.g. barnacles, algae) from the carapace and sanded and cleaned it with isopropyl alcohol. We streamlined attachment materials and minimized the epoxy footprint. Each tag had an anticipated battery life of 1 yr and was programmed to operate continuously. All turtles were released within $2 \mathrm{~h}$ at their capture location.

For acoustic tags, we outfitted selected turtles with Vemco V16-4L acoustic transmitters (25 g in air, $11 \mathrm{~g}$ in water; $16 \mathrm{~mm}$ diameter $\times 68 \mathrm{~mm}$ length), programmed for a $90 \mathrm{~s}$ time interval, on the right rear carapace marginal scute, using approx. half of a West Marine epoxy putty stick, mixed immediately prior to application. We streamlined the epoxy and minimized its footprint. The drying time was 1 to $1.5 \mathrm{~h}$, depending on air temperature at the time of attachment. The anticipated life of each tag was about $3 \mathrm{yr}$.

\section{Home ranges and core areas}

\section{Site fidelity test and kernel density estimations}

Argos Doppler data provides location error estimates (location class: LC) with each point. Argos assigns accuracy estimates of $<250 \mathrm{~m}$ for LC 3, 250 to $<500 \mathrm{~m}$ for LC 2, 500 to $<1500 \mathrm{~m}$ for LC 1, and $>1500 \mathrm{~m}$ for LC 0 (CLS 2011, also see Witt et al. 2010 for on-animal location estimates). The estimated accuracy is unknown for LCs A and B (A and B differ in number of received messages), and locations failing the Argos plausibility tests are tagged as class LC Z (CLS 2011). Following Eckert (2006), we applied the Douglas Argos-Filter for satellite data keeping the highest 3 location classes (LC 0-2), and using a speed filter of $3 \mathrm{~km} \mathrm{~h}^{-1}$ based on Dujon et al. (2014), who assumed the average swim speed of green turtles to be $2.5 \mathrm{~km} \mathrm{~h}^{-1}$. We used 15 for the angle parameter setting (about $26^{\circ}$ ), and a maximum radius of $2 \mathrm{~km}$, and we also removed apparent erro- neous locations ( $<1 \%$ of the data). Using the filtered locations, we conducted a correlated random walk (CRW) site-fidelity test within $65 \mathrm{~km}$ isobaths (this bathymetry contour ranged 15 to $>30 \mathrm{~km}$ from the DRTO boundary). Following the mean positioning method (Simpfendorfer et al. 2002), we derived hourly positions from acoustic data. With filtered satellite and mean positioned acoustic locations, we derived mean daily locations of each turtle to minimize correlation. We created 50 and 95\% kernel density estimations (KDEs) for each turtle to represent the core area of activity and the home range using the least square cross-validation method. We used the adhabitat package (Calenge 2006) for R (http://r-project.org) for the CRW site fidelity test and KDE.

Benthic type, seagrass density, and bathymetry in core areas

We used 3 ancillary data sets to characterize the core area: vector data of benthic types released by the National Park Service (http://science.nature. nps.gov/im/units/sfcn/monitor/landscape/benthic_ mapping.cfm, accessed on November 5, 2014; Waara 2011), vector data of seagrass coverage obtained from Fish and Wildlife Research Institute's Marine Resources Geographic Information System (MRGIS; http://ocean.floridamarine.org/mrgis/Description Layers_Marine.htm, accessed January 31, 2014), and a $1 \mathrm{~m}$ resolution bathymetry raster with $0.1 \mathrm{~m}$ accuracy derived from a combination of NOS sounding, multi-beams, and light detection and ranging (lidar; J. Luo unpubl. data). We combined all individual core areas (50\% KDEs) and calculated the number of 350 $\times 350$ grid cells, which roughly corresponded to the mean benthic patch size, for 13 benthic types and 3 seagrass types (continuous, discontinuous, none; Fig. 1) within and outside of the combined core area. We tested for differences in the probability of seagrass coverage on benthic types within and outside of the combined core area using a chi-squared test. In this analysis, 2 groups of compared areas were within and outside of core areas with a sample unit of $350 \times 350 \mathrm{~m}$ grid cells. We also compared grid cell bathymetry within and outside of the combined core area using a Wilcoxon rank sum test.

\section{Core area overlap indices}

Overlap indices are useful to quantitatively measure habitat sharing and the degree of interaction 
among individuals (Fieberg \& Kochanny 2005). For every combination of satellite-tagged turtles in each year, we calculated the core area overlap indices including the proportion of animal $i$ 's core area overlapped by animal $j$ 's core area $\left(\mathrm{HR}_{i, j}\right)$, the probability of animal $j$ being located in animal $i$ 's core area $\left(\mathrm{PHR}_{i, j}\right)$, and the utilization distribution overlap index (UDOI) (Fieberg \& Kochanny 2005). HR $_{i, j}$ is a simple measure to quantify static overlap whereas $\mathrm{PHR}_{i, j}$ considers relative probability of use; both range from 0 to 1 (Fieberg \& Kochanny 2005). The UDOI, a generalization of Hurlbert's (1978) $E / E_{\text {uniform }}$ statistic, is a function of 2 utilization distributions and ranges from 0 (no overlap) to 1 (100\% overlap). The UDOI is recommended (Fieberg \& Kochanny 2005) to measure space use sharing over other indices. Each turtle combination was classified into one of the 3 possible gender combinations: female-male (FM), femalefemale $(\mathrm{FF})$, and male-male (MM).

\section{Analysis of acoustic detection data}

Pedersen \& Weng (2013) demonstrated that acoustic telemetry data at fixed locations are useful to estimate detection probabilities of marine fish. In this study, as the array does not cover the entire study area, we considered each station as a point sample location. Because acoustic receivers are passive monitoring tools within a limited detection range (a few hundred meters; Hazel et al. 2013), an absence of observations (detections) implies that either (1) turtles are not present within receiver detection range but are present in the study area, (2) turtles are within receiver detection range but there are impediments to transmission, or (3) turtles left the study area. To avoid non-detection caused by (3), we only used acoustic detection data when all acoustically tagged turtles were confirmed inside DRTO either by satellite or acoustic data. In addition, because receiver batteries died or receivers were removed for maintenance, we only analyzed data when all receivers were deployed and active to ensure nondetections were not caused by receivers malfunctioning. The detection distance of acoustic receivers can vary based on transmitter type, salinity and depth of water, ambient noise, presence of pycnoclines and thermoclines, and the behavior of the study animal (Heupel et al. 2006). By reviewing studies mainly on invertebrates and fish, Kessel et al. (2014) reported the maximum distance for 100,95 , and $50 \%$ detection probability was about 200,350 , and $550 \mathrm{~m}$, respectively, from the receiver. Range testing on green turtles in a coral habitat showed that the detection was near perfect up to $50 \mathrm{~m}$ and reduced to 50 and $11 \%$ at 300 and $300-400 \mathrm{~m}$ distances, respectively (Hazel et al. 2013).

\section{Detection probability at stations}

We modeled the detection probability for each year at a receiver, using the binomial distribution, that is:

$$
n_{i j k} \sim \operatorname{binomial}\left(p_{i j k}, N_{k}\right)
$$

and

$$
\begin{aligned}
& \log \left(\frac{p_{i j k}}{1-p_{i j k}}\right)=B_{0}+B_{1} \times \text { Bathymetry }_{i} \\
& +B_{2} \times \text { Benthic }_{i}+B_{3} \times D_{i j}+\varepsilon_{i}+\varepsilon_{j}+\varepsilon_{k}
\end{aligned}
$$

where $n_{i j k}$ is a number of detected days for station $i_{\text {, }}$ turtle $j$, and year $k, N_{k}$ is the number of days receivers are deployed in year $k$, and $p_{i j k}$ is the detection probability. Bathymetry ${ }_{i}$ and Benthic $_{i}$ represent bathymetry and benthic type at station $i_{1} D_{i j}$ is the distance between station $i$ and the capture location of turtle $j$, and $B_{0}, B_{1}, B_{2}, B_{3}$ are coefficients. Benthic type is a variable with 3 categories: low profile remnant (reef), continuous/discontinuous submerged rooted vascular plants (SRV), and unconsolidated sediment. Distance to the capture location was included in the analysis because it may influence the turtle occurrence if high site fidelity at the capture location is true. Variability by acoustic station, turtle, and year were accounted for as random effects, $\varepsilon_{i r} \varepsilon_{j}$, and $\varepsilon_{k}$.

\section{Detection probability of turtles}

We modeled the probability of turtle detection in a daily and seasonal (course of study period in each year) scale for each year separately using the binomial-logit model. Daily detection probability was modeled as:

$$
t_{i l} \sim \operatorname{binomial}\left(p_{i l}, T\right)
$$

and

$$
\log \left(\frac{p_{i l}}{1-p_{i l}}\right)=B+\varepsilon_{i}+\varepsilon_{1}
$$

where $t_{i l}$ is the number of detected turtles and $p_{\text {il }}$ is the detection probability in station $i(i=1,2 \ldots 7)$ at day $l$ (the range of $l$ varies by year) and $T$ is the number of acoustically tagged turtles in each year. The conditional probability of detecting multiple turtles 
daily given at least one turtle detection was calculated for each year as:

$$
p(t \geq 2 \mid t \geq 1)=\frac{\sum_{t=2}^{T} p_{t}}{\sum_{t=1}^{T} p_{t}}
$$

where $t$ is the number of detected turtles, $T$ is the number of tagged turtles in the modeled year, and $p_{t}$ is the detection probability of $t$ turtle(s).

Seasonal detection probability was modeled in a similar way:

$$
t_{i} \sim \operatorname{binomial}\left(p_{i}, T\right)
$$

and

$$
\log \left(\frac{p_{i}}{1-p_{l}}\right)=B+\varepsilon_{1}
$$

where the notation for $t, p, T$ and the subscript $i$ are the same as the daily model.

We assumed non-informative prior distributions for the variance components, $\sigma_{\text {station, }} \sigma_{\text {year }}$ and $\sigma_{\text {turtle }}$ (Uniform $(0,10)$ ), and estimated model parameters using Gibbs sampling (20000 draws obtained by sampling 5 independent Markov chains - each run for 40000 iterations after 10000 burn-ins and thinned by 10 samples) using WinBUGS 1.4 (Spiegelhalter et al. 2002) followed by Gelman-Rubin diagnostics to confirm approximate convergence using the CODA package in R (Brooks \& Gelman 1998).

\section{Gender combinations}

We examined whether multiple turtle detections occurred more frequently in particular gender combinations (i.e. FM, FF, MM). We compared the number of days each combination of turtles was detected by gender combination. Because of unequal numbers of each gender combination and the duration of receiver deployments in each year, we compared the detection data to a hypothetical detection scenario. For the hypothetical numbers, we used the maximum possible detection dates for all possible gender combinations. We then used a chi-squared test for differences in probabilities to compare the detection frequency by gender combinations.

\section{Temporal analysis}

We calculated the time (in seconds) between consecutive detections (step-time) of different individuals within the range of the same receiver. Then we examined whether the step time was different for varying gender combinations using a Kruskal-Wallis test.

\section{RESULTS}

\section{Satellite and acoustic data}

We deployed satellite tags on 15 turtles (9 males [M1 to M9], 6 females [F1 to F6]) between 2009 and 2012 (6 in 2009, 2 in 2010, 3 in 2011, and 4 in 2012) of which 13 turtles were also given acoustic tags (5 in 2009, 2 in 2010, 2 in 2011, and 4 in 2012; Table 1). Based on SCL, turtles were subadult-sized $(n=5)$ and adult-sized $(\mathrm{n}=10)$. Tracking durations of individual turtles ranged from 40 to $226 \mathrm{~d}(\bar{x} \pm 1 \mathrm{SD}=105.9 \pm$ $57.5 d_{i}$ Table 1). During this time, we received 11389 total filtered locations across all turtles, ranging from 172 to 1411 per turtle. The number of daily satellitedetected days ranged from 39 to $176 \mathrm{~d}$ per turtle. Of 15 satellite-tracked turtles, 14 tracks ended within $5 \mathrm{~km}$ of DRTO and 1 was detected beyond $5 \mathrm{~km}$ of DRTO but within FKNMS.

We used acoustic detection data from June 14 to July 20 in 2009 (36 d), June 6 to September 6 in 2010 (95 d), July 18 to September 3 in 2011 (52 d), and July 11 to August 27 in 2012 (47 d). The number of acoustic detections was highly variable across the stations and ranged from 0 to 4745 total detections, occurring on 0 to 89 unique days (Table 2). The highest number of detections occurred at station A and there were no detections at station B. All acoustically tagged turtles except one adult male (M5) were detected near at least one station (Table 1). The total number of detections per turtle ranged from 0 to 3622 $(\bar{x}=679.9, \mathrm{SD}=1002.7)$ and occurred over 0 to 51 unique days $(\bar{x}=21.9, \mathrm{SD}=18.7)$. The maximum detection period was $135 \mathrm{~d}$ (F3).

\section{Site fidelity, core areas, home ranges, and overlap indices}

All satellite-tagged turtles exhibited high site fidelity around DRTO; the results of CRW showed that all randomly generated paths had greater $\mathrm{R}^{2}$ values than true paths, suggesting that the turtle's movements were more spatially constrained rather than randomly distributed. The size of core areas $(50 \% \mathrm{KDE})$ ranged from 1.3 to $18.9 \mathrm{~km}^{2}$ and home ranges (95\% $\mathrm{KDE}$ ) ranged from 8.8 to $131.5 \mathrm{~km}^{2}$ (Fig. 2, Table 1). All core areas and home ranges occurred around a northeast portion of DRTO (Fig. 2).

There were 25 possible 2-turtle combinations of satellite-tagged individuals, including 15 FM, 7 MM, and $3 \mathrm{FF}$ combinations. At least one combination had intersecting core areas each year (Table 3). Core area inter- 


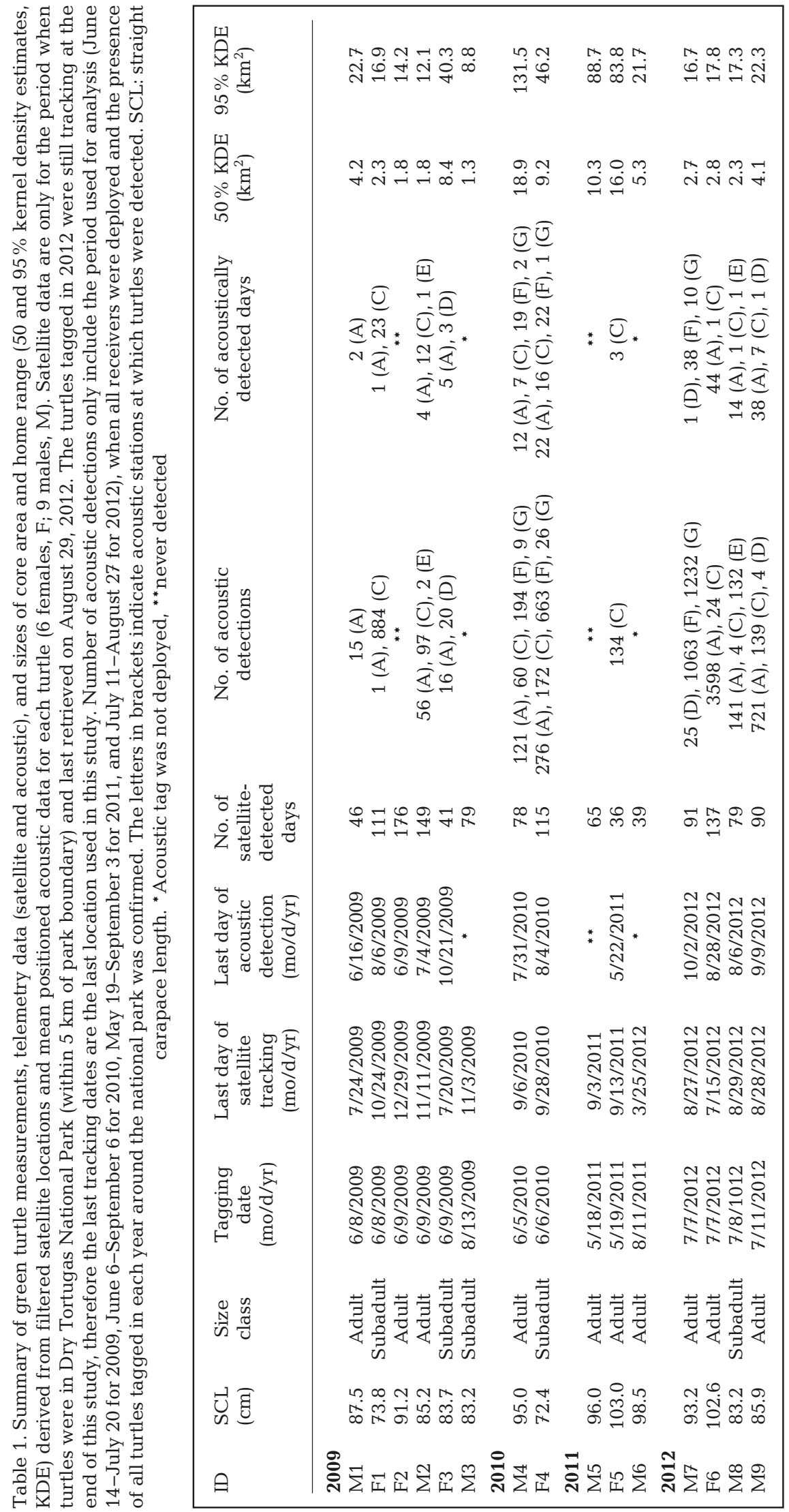

sections occurred between 9 FM, $1 \mathrm{MM}$, and $1 \mathrm{FF}$ combination. The static measure of overlap proportion, $\mathrm{HR}_{i, j}$, was highly variable ranging from 0 to 0.27 , whereas $\mathrm{PHR}_{i, j}$ was more conservative, ranging from 0 to 0.16 . Overall, UDOI was small (0 to 0.003), suggesting a small degree of space sharing between individuals.

\section{Habitat type}

The proportion of each benthic type within and outside of the areas encompassing all the core areas in DRTO was significantly different $\left(\chi^{2}=128.5, \mathrm{p}<0.0001\right)$. This difference appeared to be attributed to a higher proportion of SRV within the core area (Fig. 3). In particular, continuous SRV was the most common benthic type within the core area (30\%), whereas it covered only a minor portion (11\%) outside (Fig. 3). Similarly, there was a higher proportion of continuous and discontinuous seagrass beds within the core area $(37 \%)$ than outside $\left(11 \%, \chi^{2}=\right.$ 178.5, p $<0.0001$, Fig. 3). The area within the combined core area was characterized by significantly (Wilcoxon $T=16.0, \mathrm{p}<0.0001$ ) shallower bathymetry depth $(\bar{x}=$ $-8.5 \mathrm{~m}, \mathrm{SD}=4.8 \mathrm{~m}$ ) than outside $(\bar{x}=-14.1 \mathrm{~m}, \mathrm{SD}=6.2 \mathrm{~m})$.

\section{Detection probability by stations}

The posteriors of model coefficients are summarized in Table 4. A positive $95 \%$ credible interval (CI) of $B_{1}$ indicated a positive association between detection probabilities and bathymetry. Contrary to this, a negative CI of $B_{3}$ indicated an inverse association between the detection probability and the distance between the acoustic station and capture location. The broad CI of $B_{2}$ that 
Table 2. Summary of bathymetry depth, benthic type of acoustic stations, and detections of green turtles. Number of detections are only for the period used for analysis (June 14-July 20 for 2009, June 6-September 6 for 2010, May 19-September 3 for 2011, and July 11-August 27 for 2012), when all receivers were deployed and the presence of all turtles tagged in each year around the Park was confirmed. Numbers in parentheses are the number of days with detections. Detection data from receivers D and E were not used for analysis due to long undeployed periods. SRV: submerged rooted vascular plants; na: not available

\begin{tabular}{|c|c|c|c|c|c|c|c|}
\hline \multirow{2}{*}{ Station } & \multirow{2}{*}{$\begin{array}{l}\text { Depth } \\
(\mathrm{m})\end{array}$} & \multirow{2}{*}{ Benthic type } & \multirow{2}{*}{$\begin{array}{l}\text { Duration } \\
(\mathrm{mo} / \mathrm{d} / \mathrm{yr})\end{array}$} & \multicolumn{4}{|c|}{ No. of detections } \\
\hline & & & & 2009 & 2010 & 2011 & 2012 \\
\hline A & 8.5 & Low profile remnant & 6/10/2009-11/7/2012 & $88(11)$ & $397(31)$ & $0(0)$ & $4240(96)$ \\
\hline $\mathrm{B}$ & 4.6 & Continuous SRV & 8/9/2008-11/7/2012 & $0(0)$ & $0(0)$ & $0(0)$ & $0(0)$ \\
\hline $\mathrm{C}$ & 9.4 & Unconsolidated sediment & $\begin{array}{c}6 / 10 / 2009-5 / 8 / 2012 \\
5 / 11 / 2012-11 / 7 / 2012\end{array}$ & $981(27)$ & $232(20)$ & $134(3)$ & $167(9)$ \\
\hline $\mathrm{D}$ & 12.8 & Unconsolidated sediment & $\begin{array}{c}\text { 6/6/2009-2/1/2011 } \\
7 / 18 / 2011-11 / 7 / 2012\end{array}$ & $20(3)$ & $9(0)$ & na & $29(2)$ \\
\hline $\mathrm{E}$ & 4.9 & Low profile remnant & 6/10/2009-11/27/2012 & $2(1)$ & $0(0)$ & na & $332(1)$ \\
\hline $\mathrm{F}$ & 9.4 & Discontinuous SRV & $\begin{array}{c}6 / 6 / 2009-2 / 7 / 2012 \\
7 / 5 / 2012-11 / 7 / 2012\end{array}$ & $0(0)$ & $857(40)$ & $0(0)$ & $1063(38)$ \\
\hline $\mathrm{G}$ & 11 & Unconsolidated sediment & 6/14/2009-11/7/2012 & $0(0)$ & $35(3)$ & $0(0)$ & $232(10)$ \\
\hline
\end{tabular}

ranged from negative to positive indicated that the association between the detection probability and benthic type was neither clearly negative nor positive.

Table 3. Indices of core area overlap for each combination of 2 satellitetracked green turtles in Dry Tortugas National Park from 2009 to 2012 including proportion of animal $i$ 's core area overlapped by animal $j$ 's core area $\left(\mathrm{HR}_{i, j}\right)$, probability of animal $j$ being located in animal $i$ 's core area $\left(\mathrm{PHR}_{i, j}\right)$, and utilization distribution overlap index (UDOI)

\begin{tabular}{|cccccccr|}
\hline Year & \multicolumn{2}{c}{ Combinations } & $\mathrm{HR}_{1,2}$ & $\mathrm{HR}_{2,1}$ & $\mathrm{PHR}_{1,2}$ & $\mathrm{PHR}_{2,1}$ & UDOI \\
& 1 & 2 & & & & & \\
\hline 2009 & F1 & F2 & 0.069 & 0.061 & 0.032 & 0.029 & 0.001 \\
& F1 & F3 & 0.000 & 0.000 & 0.000 & 0.000 & 0.000 \\
& F2 & F3 & 0.000 & 0.000 & 0.000 & 0.000 & 0.000 \\
& M1 & M2 & 0.000 & 0.000 & 0.000 & 0.000 & 0.000 \\
& M1 & M3 & 0.000 & 0.000 & 0.000 & 0.000 & 0.000 \\
& M2 & M3 & 0.000 & 0.000 & 0.000 & 0.000 & 0.000 \\
& F1 & M1 & 0.000 & 0.000 & 0.000 & 0.000 & 0.000 \\
& F1 & M2 & 0.034 & 0.029 & 0.015 & 0.014 & $<0.001$ \\
& F1 & M3 & 0.000 & 0.000 & 0.000 & 0.000 & 0.000 \\
& F2 & M1 & 0.060 & 0.074 & 0.033 & 0.031 & 0.001 \\
& F2 & M2 & 0.000 & 0.000 & 0.000 & 0.000 & 0.000 \\
& F2 & M3 & 0.000 & 0.000 & 0.000 & 0.000 & 0.000 \\
& F3 & M1 & 0.016 & 0.037 & 0.018 & 0.010 & $<0.001$ \\
& F3 & M2 & 0.000 & 0.000 & 0.000 & 0.000 & 0.000 \\
& F3 & M3 & 0.063 & 0.235 & 0.098 & 0.031 & 0.003 \\
2010 & F4 & M4 & 0.090 & 0.025 & 0.010 & 0.045 & $<0.001$ \\
2011 & F5 & M5 & 0.216 & 0.142 & 0.085 & 0.111 & 0.009 \\
& F5 & M6 & 0.000 & 0.000 & 0.000 & 0.000 & 0.000 \\
& M5 & M6 & 0.012 & 0.083 & 0.056 & 0.006 & $<0.001$ \\
2012 & F6 & M7 & 0.000 & 0.000 & 0.000 & 0.000 & 0.000 \\
& F6 & M8 & 0.082 & 0.273 & 0.162 & 0.027 & 0.004 \\
& F6 & M9 & 0.034 & 0.167 & 0.081 & 0.010 & 0.001 \\
& M7 & M8 & 0.000 & 0.000 & 0.000 & 0.000 & 0.000 \\
& M7 & M9 & 0.000 & 0.000 & 0.000 & 0.000 & 0.000 \\
& M8 & M9 & 0.091 & 0.091 & 0.086 & 0.040 & 0.004 \\
\hline
\end{tabular}

Daily and seasonal detection probability

The posterior probability of daily detection was generally low; the estimated probability of no detection was over 0.89 in all years (Table S1, Fig. S1A in the Supplement at www.intres.com/articles/suppl/b024p185_supp.pdf). The estimated probability of 1 turtle detection was $<0.1$, and that of multiple turtle detections ( $>1$ individual) was even lower, (maximum of 0.13). However, the probability of multiple turtle detections was much higher when it was conditioned on at least one individual being detected, and ranged from 0.0004 to 0.045 (Fig. S1C). Also, within-season detection probability was much higher (Fig. S1B); in 2009, the year in which the largest number of turtles were acoustically tagged $(\mathrm{n}=5)$, seasonal detection probabilities for 1 to 5 turtles were 0.038,0.006, 0.002, 0.001, and $<0.001$. In 2012, when 4 turtles were tagged, the seasonal detection probabilities for 1 to 4 turtles were 0.369, 0.256, 0.099 and 0.019 .

\section{Comparison by gender combination}

Over all years, there were 52 days in which unique FM combinations were detected and 11 days when unique MM combinations were detected on the same day at the same station. Detection of FF 


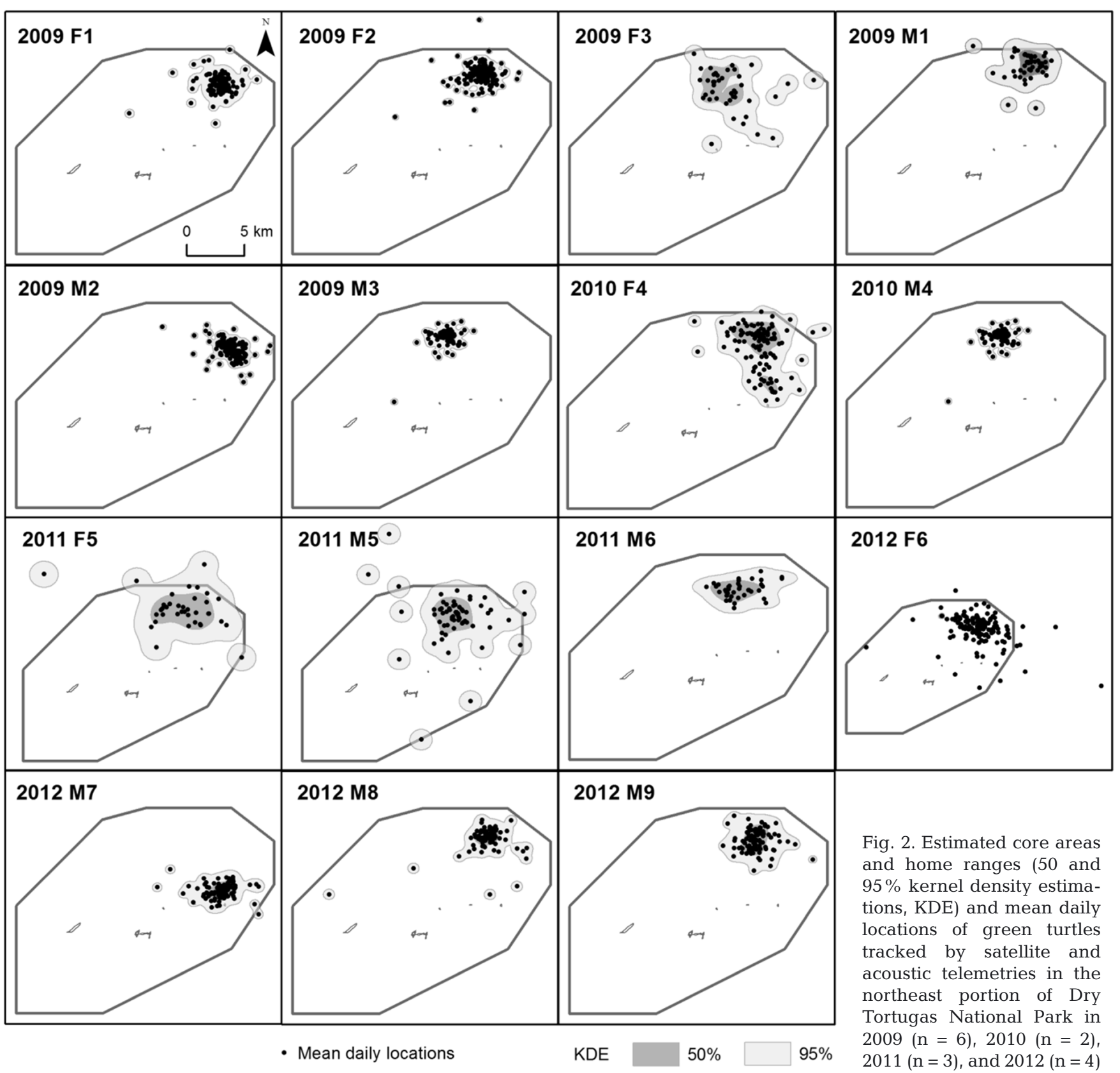

combinations was possible in 2009 because multiple females were acoustically tagged, but it did not occur. When we tested the proportion of detected days for same gender combinations (FF and MM combinations, $17.5 \%$ ) and different gender combinations (FM, 82.5\%) against the maximum possible detection rate $(37 \%$ for $\mathrm{FF}$ and $\mathrm{MM}$ combinations and $63 \%$ for FM combinations), the result was significant $\left(\chi^{2}=10.32, p=0.023\right)$ : the FM combinations were detected on a disproportionally larger number of days.

\section{Temporal analysis}

There were 415 observations in which 6 unique turtle combinations (Fig. 4A) were consecutively detected at the same station in a single day. The step-time was highly variable, ranging from $4 \mathrm{~s}$ to $13.9 \mathrm{~h}$, and was skewed (Fig. 4B): $40 \%$ of 2 turtle detections occurred within $1 \mathrm{~min}, 71 \%$ of them occurred within $5 \mathrm{~min}$ and the frequency of 2 turtle detections declined along increasing time intervals. The KruskalWallis test indicated that step-time was different 

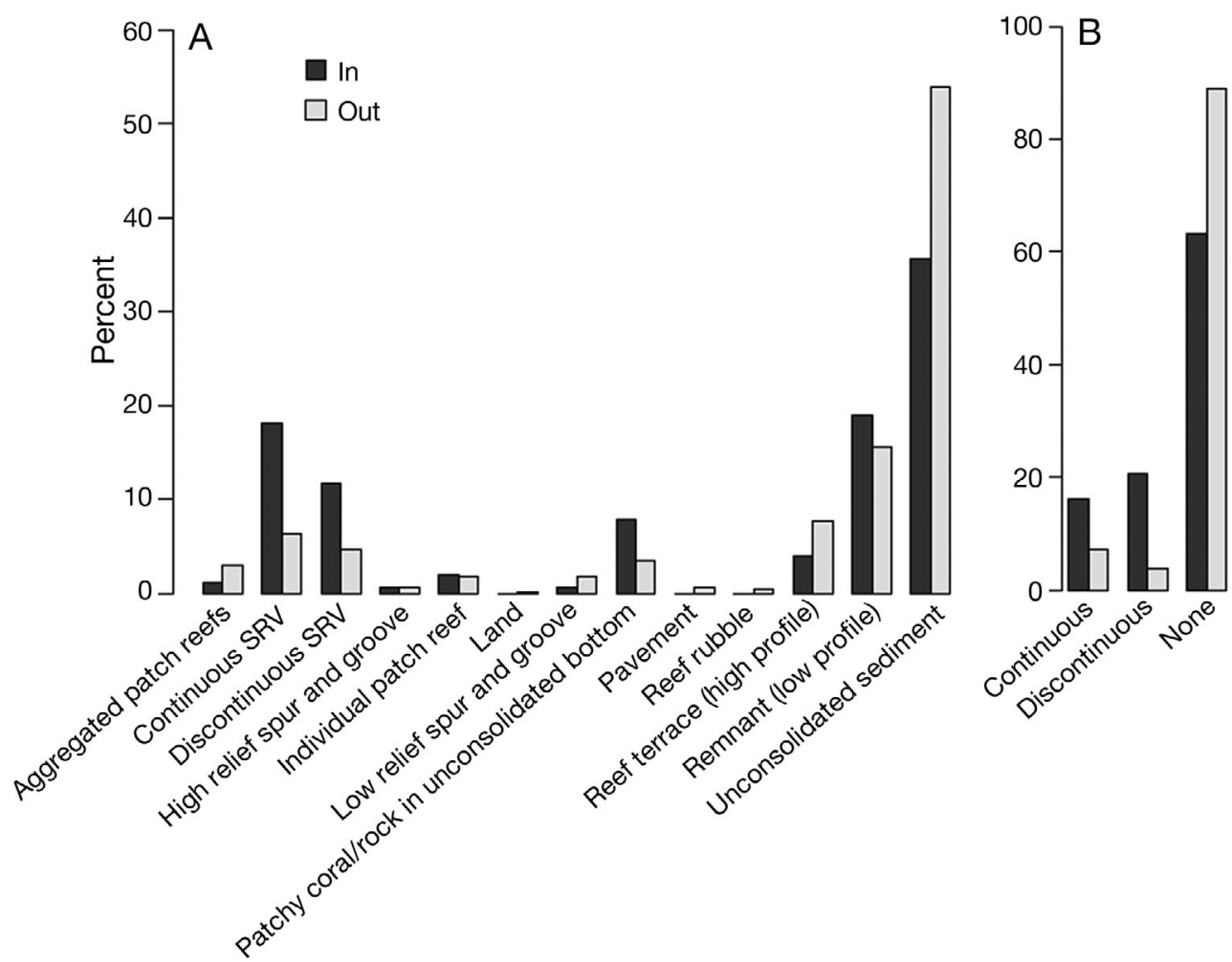

Fig. 3. Area by (A) benthic type and (B) seagrass category in and out of combined core areas (50\% kernel density estimations) from satellitetagged green turtles $(\mathrm{n}=$ 15) in Dry Tortugas National Park. Note difference in scale between $\mathrm{A}$ and B. SRV: submerged rooted vegetation

among turtle combinations $\left(\chi^{2}=13.04, p=0.023\right.$, Fig. 4B), but we did not observe a consistent trend of step-times differing between same and different gender combinations.

\section{DISCUSSION}

Tropical and subtropical neritic zones are productive areas maintaining a high biodiversity of marine life. While a variety of marine species use the neritic zone, knowledge of spatial-temporal variation in habitat selection by highly mobile large vertebrates within this ecologically important area is limited.

Table 4. Posterior summary (mean, SD, median, and 95\% credible interval) of parameters for the model of daily detection probability at acoustic stations estimated by acoustic detection data. $B_{0}, B_{1}, B_{2}, B_{3}$ are intercept and coefficients for bathymetry depth, benthic type (low profile remnant, continuous/discontinuous SRV, and unconsolidated sediment) and distance to the capture location, respectively. SRV: submerged rooted vascular plants

\begin{tabular}{|lrrrrr|}
\hline Parameter & Mean & SD & $2.5 \%$ & Median & $97.5 \%$ \\
\hline$B_{0}$ & -16.3400 & 21.3100 & -51.6500 & -21.8800 & 26.1400 \\
$B_{1}$ & 1.3050 & 0.6507 & 0.1761 & 1.2700 & 2.5890 \\
$B_{2 \text { (low profile remnant) }}$ & 4.3620 & 19.1700 & -35.6600 & 9.2350 & 30.6700 \\
$B_{2 \text { (continuous/discontinuous SRV) }}$ & 1.6910 & 19.6100 & -37.9600 & 4.0580 & 31.6500 \\
$B_{2}$ (unconsolidated sediment) & -0.3214 & 18.2600 & -36.4100 & 1.1490 & 28.6700 \\
$B_{3}$ & -0.9265 & 0.2302 & -1.3720 & -0.9280 & -0.4768 \\
\hline
\end{tabular}

\section{Site fidelity and core area size}

During tracking periods the majority of turtles stayed within $5 \mathrm{~km}$ of the DRTO boundary and none demonstrated migratory behavior. This observation aligns with our previous study of nesting green turtles Chelonia mydas in DRTO which found that the majority of satellitetracked turtles were year-round residents within DRTO and FKNMS (Hart et al. 2013). Studies in other areas have also suggested high site fidelity of green turtles between successive breeding seasons (Limpus et al. 1992, Broderick et al. 2007, Stokes et al. 2015). Therefore, it is possible these turtles are long-term residents within DRTO and FKNMS; however, no turtle was acoustically detected in subsequent years after tagging. The last observations within DRTO occurred 

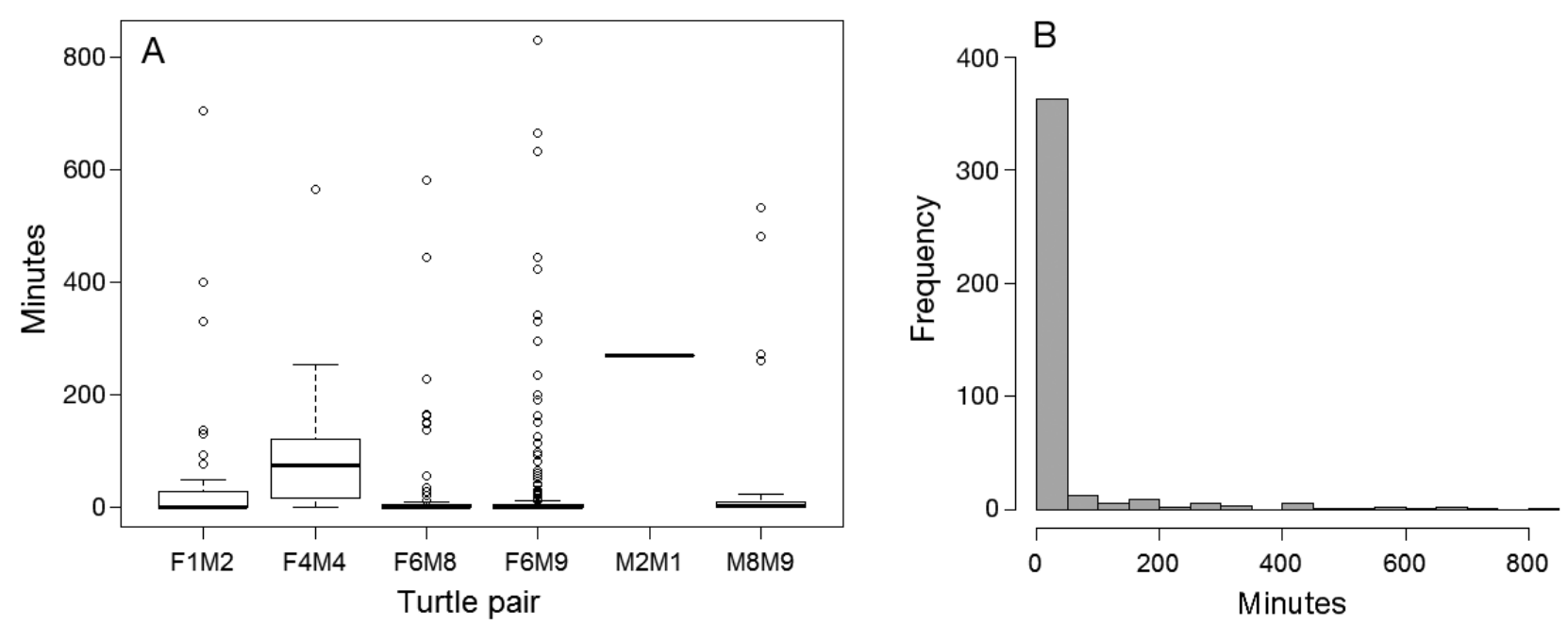

Fig. 4. (A) Box-plots of observed step-time (time interval in minutes between consecutive detections of different green turtles at a single acoustic station in the same day) by turtle combinations and the (B) frequency of the observed step-times with all combinations based on detections by acoustic receivers deployed in Dry Tortugas National Park from 2009-2012 with 13 acoustically tagged turtles

more often with satellite telemetry than acoustic telemetry; of 13 turtles tracked by both methods, only 3 were acoustically detected later than satellite detections (Table 1). This implies that turtles eventually left DRTO or moved into another area within DRTO, or that the acoustic tag detection/retention duration was much shorter than we expected.

As demonstrated by previous studies (see reviews by Godley et al. 2008, Hart \& Hyrenbach 2009), this study also shows that satellite data are useful for delineating individual core areas and home ranges. Core areas of all 15 turtles satellite-tracked in this study were concentrated in the seagrass-rich northern part of DRTO, which is similar to previously identified core areas for other nesting green turtles in DRTO (Hart et al. 2013). However, because our turtles were caught in the same general area in DRTO, the distribution of core areas for the entire green turtle population in the park is unclear. Tracking turtles caught in different parts of DRTO would help to better understand the use of benthic resources by the green turtle population in the park.

The estimated home-range size of tagged turtles in this study $\left(8.8-131.5 \mathrm{~km}^{2}\right)$ was comparable to that of turtles foraging in the Gulf of California (4.1$32.3 \mathrm{~km}^{2}$, Seminoff et al. 2002) and of juveniles in the Big Sable Creek Complex in southwest coastal Everglades National Park, Florida (24.6-371.0 km², Hart \& Fujisaki 2010), but was much smaller than estimates from foraging sites off the coast of Tamaulipas, Mexico and Texas (406.3-4944.4 km²; Shaver et al. 2013). This difference may reflect varied spatial arrangements of suitable habitat among study sites (Schofield et al. 2010).

\section{Core area selection}

The higher proportion of seagrass cover within core areas as compared to the rest of DRTO suggests that our turtles consistently inhabit areas with high resource availability. The seagrass area is generally shallow, surrounded by coral-reef platforms, and only covers a small portion of the park (about $15 \%$ of DRTO when continuous and discontinuous seagrass habitat is combined; Fig. 1). This small area coupled with the high concentration of core areas there underscores the potential issue of habitat degradation due to overgrazing; this has been a problem at other locations such as Indonesian marine protected areas in the Indian Ocean (Agatti Lagoon and Lakshadweep Islands; Lal et al. 2010, Kelkar et al. 2013, Christianen et al. 2014). An aerial survey reported high abundance of green turtles (ca. 600000) in a small geographic area in Torres Strait, Australia (Fuentes et al. 2015). However, currently there are no abundance estimates for green turtles in DRTO and therefore it is uncertain whether there are sufficient resources to sustain the population. Given the reported increases of green turtles due to conservation efforts elsewhere (Christianen et al. 2014), a future increase in green turtles at DRTO as a result of current conservation efforts is possible. Our results highlight the importance of maintaining the seagrass 
habitat as well as obtaining population estimates of green turtles in DRTO.

Core areas from multiple turtles overlapped each year, which indicates some level of habitat sharing, but overall UDOI was small $(<0.01$; Table 3$)$, suggesting a restricted degree of habitat sharing. It is unclear whether the observed habitat sharing was simply an aggregation to resources or if turtles used the presence of others in habitat selection. Because we caught the turtles in water, the nesting status of the females was uncertain; however, much of the tracking period coincided with known breeding periods and thus courtship behavior was possible, as we observed mating pairs of green turtles in the study area during these years (K. M. Hart pers. obs). Although in this study we did not have enough satellite-tracked subadult turtles or data outside of the nesting season, future comparisons of overlapped core areas by size class and season could illuminate the effect of mating activities on habitat selection.

\section{Detection probability by acoustic telemetry}

Analysis with the receiver detection model showed that use of specific locations monitored by acoustic telemetry is dictated by spatial factors, especially proximity to capture sites and water depth. Our receivers were deployed within depth classes that green turtles use the most extensively within a coastal foraging area $(0-10 \mathrm{~m}$ and $10-20 \mathrm{~m}$; Seminoff et al. 2002). As stated above, satellite data indicated that core areas were concentrated in generally shallow water in DRTO, but within this shallow range where receivers were deployed $(4.6-12.8 \mathrm{~m})$ the detection probability increased in deeper water. This could imply both (1) that turtles occupied areas only a few meters deep less frequently and (2) that detection range varied by water depth, especially in shallow water (Kessel et al. 2014). The model also indicated that the detection probability was higher when it was closer to capture sites, which supports high site fidelity. Because all turtles in this study were caught in the northeast of DRTO within a $2 \mathrm{~km}$ range (Fig. 2), the inverse association between detection probability and capture site indicates that this is a central activity area for our turtles.

On a daily basis, the detection probability of a turtle at a station was slim in any study year and the probability of detecting multiple turtles at the same station was even smaller. The conditional probability of multiple turtle detections - the probability of detection given at least one turtle was detected was much larger. The overall small probability estimates of multiple turtle detections do not support conspecific attraction, but estimates of conditional probabilities were not small enough to support conspecific avoidance, particularly given the small sample size. Notably, the estimated conditional probability of multiple turtle detection tended to be larger in years when more turtles were acoustically tagged. In fact, we have many sightings of green turtles in close proximity, sometimes even within $1 \mathrm{~m}$ (K. M. Hart pers. obs). Therefore, multiple turtle detections likely occur more frequently throughout the entire population of green turtles in DRTO. Again, understanding the population size of green turtles in DRTO would provide more insight into co-occupancy patterns.

The temporal analysis showed a clear pattern that multiple turtle detections occurred within a short period of time, even within a few seconds. This observation further supports that multiple turtles share habitat on smaller spatial and temporal scales. On a seasonal scale, the detection probability of both single and multiple turtles was much higher compared to the daily detection probability. For example, the posterior mean of multiple turtle detections in 2012 was about 0.37 during the course of the season. This result suggests that multiple turtles more likely use a common location over a longer temporal span, as would be expected based on the overlapping core areas observed by the satellite data.

The acoustic data also showed gender effects on specific habitat use, possibly reflecting courtship behavior (Lanyon et al. 1989). We observed a disproportionally higher amount of FM combination detections as compared to same gender combinations. We did not detect any FF combinations even though it was possible. This result is potentially because of femalefemale aggression as reported for loggerheads (Schofield et al. 2007); however, the temporal analysis did not show step-time differences by gender combination, in part due to the large variability and the small number of combinations detected in the same day.

The acoustic data results show increased conditional detection probabilities of multiple turtles and co-occupancy at a receiver within a short period of time. This, combined with the satellite results showing overlapping core areas, indicate that these turtles are not necessarily territorial, despite the fact that each turtle establishes a unique core area and home range and small degree of habitat sharing. 


\section{Combining telemetry technologies}

Sea turtle habitat selection was not well understood until various automatic tracking techniques emerged, due to the high mobility and aquatic nature of the species. Novel uses of technology and the integration of data have become increasingly important to answer remaining questions on their ecology (Hazen et al. 2012). Combining satellite and acoustic telemetries is an effective method for defining and characterizing the habitats of marine species on multiple spatial and temporal scales, as shown by this study and in our previous DRTO study of hawksbills Eretmochelys imbricata (Hart et al. 2012). A recent study also showed that the combination of animalborne acoustic and GPS tracking was useful to examine the pattern of predator-prey interactions in water (Lidgard et al. 2014). There are a few critical issues we encountered in using data from satellite and acoustic tracking, though combining the 2 techniques mitigated the drawbacks associated with each technique. Although active detection with satellite telemetry enables continuous monitoring and lower costs compared to GPS telemetry, it comes with a large uncertainty in location accuracy (Vincent et al. 2002). This potentially large location error constrains conducting analyses on factors that may influence habitat selection in a highly heterogeneous environment. Acoustic telemetry can address this shortfall by providing more spatially explicit information on habitat use while being a cost-effective tracking method for species that establish a home range (Zeh et al. 2015). One clear disadvantage with acoustic telemetry, however, is the uncertainty in obtaining detection records, as data collection depends on array size and animal movements. We obtained a vast number of acoustic detections, but this was dramatically reduced when we removed duplications for daily analysis. Further, 1 tagged turtle was never acoustically detected, although satellite data confirmed this turtle was in DRTO, and there was 1 station with no detections despite its close proximity to the capture site. Additionally, all turtles had shorter than expected acoustic tracking periods, which may be due to the attachment method. Another concern with acoustic telemetry is tag/receiver failure. To avoid the effect of false absence on our detection probability estimates, we had to exclude records from 2 receivers during a time of battery failure. These uncertainties associated with acoustic telemetry may be mitigated by (1) ensuring the array of receivers covers the area of interest, (2) tagging a large number of study animals, (3) servicing equipment every few months to ensure receiver recording status and detect false absences, and (4) use of sentinel tags for range detection and receiver testing. We also note that although we selected satellite and acoustic telemetry due to logistical goals and constraints, GPS telemetry is another technique potentially effective to both quantify the core area and co-occupancy with high location accuracy (Witt et al. 2010).

\section{CONCLUSIONS}

Our study provided numerical estimates of core area overlap, co-occupancy probabilities, and habitat characterization for green turtles Chelonia mydas. Our results suggest that our turtles established unique and partially overlapping core areas, and cooccupancy, although it was observed, was relatively rare. A high concentration of core areas highlights the importance of obtaining population estimates to understand resources needed to sustain the population in the face of declining seagrass ecosystems (Orth et al. 2006) and better inform the estimated cooccupancy probability. The results also suggest that habitat selection may in part be mediated by gender. Population estimates through recapture studies, in conjunction with acoustic telemetry, may reveal how much habitat overlap occurs in the entire green turtle population within the study area.

Acknowledgements. We acknowledge assistance from National Park Service employees Kayla Nimmo, Tree Gottshall, Tracy Ziegler, and Captains John Spade, Janie Douglass, and Blue Douglass. We are grateful to USGS volunteers and employees K. Ludwig, B.J. Reynolds, M. Cherkiss, T. Selby, B. Smith, M. Denton, B. Jeffrey, J. Beauchamp, and others. All research on green turtles was conducted according to institutional and animal care protocols (USGS-SESCIACUC-2011-05), and was authorized by Dry Tortugas Scientific Research Permits DRTO-2008 -SCI-0008, DRTO-2010 -SCI-0009, DRTO-2012-SCI-0008, State of Florida Marine Turtle Permit 176 (issued to K. Hart), and National Oceanic and Atmospheric Administration National Marine Fisheries Endangered Species permit 13307 (issued to K. Hart). Any use of trade, product, or firm names is for descriptive purposes only and does not imply endorsement by the US Government.

\section{LITERATURE CITED}

Bjorndal KA (1980) Nutrition and grazing behavior of the green turtle (Chelonia mydas). Mar Biol 56:147-154

Bjorndal KA (1985) Nutritional ecology of sea turtles. Copeia 1985:736-751

Bjorndal KA (1997) Foraging ecology and nutrition of sea turtles. In: Lutz PL, Musick JA (eds) The biology of sea turtles. CRC Press, Boca Raton, FL, p 199-231 
Bjorndal KA, Jackson JBC (2003) Roles of sea turtles in marine ecosystems: reconstructing the past. In: Lutz PL, Musick JA, Wyneken J (eds) The biology of sea turtles, Vol II. CRC Press, Boca Raton, FL, p 259-273

Bolten AB (2003) Variation in sea turtle life history patterns: neritic vs. oceanic development stages. In: Lutz PL, Musick JA, Wyneken J (eds) The biology of sea turtles, Vol II. CRC Press, Boca Raton, FL, p 243-257

Bouchard SS, Bjorndal KA (2000) Sea turtles as biological transporters of nutrients and energy from marine to terrestrial ecosystems. Ecology 81:2305-2313

Bresette MJ, Witherington BE, Herren RM, Bagley DA and others (2010) Size-class partitioning and herding in a foraging group of green turtles Chelonia mydas. Endang Species Res 9:105-116

Broderick AC, Coyne MS, Fuller MJ, Glen F, Godley BJ (2007) Fidelity and over-wintering of sea turtles. Proc R Soc B 274:1533-1538

Brooks SP, Gelman A (1998) General methods for monitoring convergence of iterative simulations. J Comput Graph Stat 7:434-455

Burkholder DA, Heithaus MR, Thomson JA, Fourqurean JW (2011) Diversity in trophic interactions of green sea turtles Chelonia mydas on a relatively pristine coastal foraging ground. Mar Ecol Prog Ser 439:277-293

Calenge C (2006) Thje package 'adehabitat' for the R software: a tool for the analysis of space and habitat use by animals. Ecol Model 197:516-519

Christianen MJA, Herman PMJ, Bouma TJ, Lamers LPM, van der Kerk MM, Kiswara W, van de Koppel J (2014) Habitat collapse due to overgrazing threatens turtle conservation in marine protected areas. Proc R Soc B 281: 20132890

CLS (2011) Argos user's manual: worldwide tracking and environmental monitoring by satellite. 19 August 2011 update. CLS, Toulouse. www.argos-system.org/web/en/ 76-user-s-manual.php

> Dall SRX, Giraldeau L, Olsson O, McNamara JM, Stephens DW (2005) Information and its use by animals in evolutionary ecology. Trends Ecol Evol 20:187-193

> Dujon AM, Lindstrom RT, Hays GC (2014) The accuracy of Fastloc-GPS locations and implications for animal tracking. Methods Ecol Evol 5:1162-1169

Eckert SA (2006) High-use oceanic areas for Atlantic leatherback sea turtles (Dermochelys coriacea) as identified using satellite telemetered locations dive information. Mar Biol 149:1257-1267

Ehrhart LM, Ogren LH (1999) Studies in foraging habitats: capturing and handling turtles. In: Eckert KL, Bjorndal KA, Abreu-Grobois FA, Donnelly M (eds) Research and management techniques for the conservation of sea turtles. Consolidated Graphic Communications, Blanchard, PA, p 1-4

Ernst C, Lovich J, Barbour R (1994) Turtles of the United States and Canada. Smithsonian Institution Press, Washington, DC

Fieberg J, Kochanny CO (2005) Quantifying home-range overlap: the importance of the utilization distribution. J Wildl Manag 69:1346-1359

- Fuentes MMPB, Bell I, Hagihara R, Hamann M and others (2015) Improving in-water estimates of marine turtle abundance by adjusting aerial survey counts for perception and availability biases. J Exp Mar Biol Ecol 471: 77-83

Garnett ST, Price IR, Scott FJ (1985) The diet of the green turtle, Chelonia mydas (L.), in Torres Strait. Aust Wildl Res 12:103-112

Godley BJ, Blumenthal JM, Broderick AC, Coyne MS, Godfrey MH, Hawkes LA, Witt MJ (2008) Satellite tracking of sea turtles: Where have we been and where do we go next? Endang Species Res 4:3-22

Groombridge B, Luxmoore R (1989) The green turtle and hawksbill (Reptilia: Cheloniidae): world status, exploitation and trade. United Nations Environment Programme, Cambridge

Hart KM, Fujisaki I (2010) Satellite tracking reveals habitat use by juvenile green sea turtles Chelonia mydas in the Everglades, Florida, USA. Endang Species Res 11: 221-232

> Hart KM, Hyrenbach KD (2009) Satellite telemetry of marine megavertebrates: the coming of age of an experimental science. Endang Species Res 10:9-20

> Hart KM, Sartain AR, Fujisaki I, Pratt HL Jr, Morley D, Feeley MW (2012) Home range, habitat use, and migrations of hawksbill turtles tracked from Dry Tortugas National Park, Florida, USA. Mar Ecol Prog Ser 457:193-207

Hart KM, Zawada DG, Fujisaki I, Lidz BH (2013) Habitat use of breeding green turtles Chelonia mydas tagged in Dry Tortugas National Park: making use of local and regional MPAs. Biol Conserv 161:142-154

Hart KM, Sartain AR, Fujisaki I (2015) Bahamas connection: Residence areas selected by breeding female loggerheads tagged in Dry Tortugas National Park, USA. Anim Biotelem 3:3

Hays GC, Webb PI, Hayes JP, Priede IG, French J (1991) Satellite tracking of a loggerhead turtle (Caretta caretta) in the Mediterranean. J Mar Biol Assoc UK 71:743-746

> Hazel J, Hamann M, Lawler IR (2013) Home range of immature green turtles tracked at an offshore tropical reef using automated passive acoustic telemetry. Mar Biol 160:617-627

> Hazen EL, Maxwell SM, Bailey H, Bograd SJ and others (2012) Ontogeny in marine tagging and tracking science: techniques and data gaps. Mar Ecol Prog Ser 457: 221-240

- Heupel MR, Semmens JM, Hobday AJ (2006) Automated acoustic tracking of aquatic animals: scales, design and deployment of listening station arrays. Mar Freshw Res 57:1-13

Hilton-Taylor C (2000) 2000 IUCN Red List of Threatened Species. IUCN, Gland

Hirth HF (1997) Synopsis of the biological data on the green turtle, Chelonia mydas (Linnaeus 1758). Biology of reptiles, US Fish Wildlife Service, Washington, DC

> How JR, de Lestang S (2012) Acoustic tracking: issues affecting design, analysis and interpretation of data from movement studies. Mar Freshw Res 63:312-324

> Hurlbert SH (1978) The measurement of niche overlap and some relatives. Ecology 59:67-77

> Kelkar N, Arthur R, Marba N, Alcovero T (2013) Green turtle herbivory dominates the fate of seagrass primary production in the Lakshadweep islands (Indian Ocean). Mar Ecol Prog Ser 485:235-243

Kessel ST, Cooke SJ, Heupel MR, Hussey NE, Simpfendorfer CA, Vagle S, Fisk AT (2014) A review of detection range testing in aquatic passive acoustic telemetry studies. Rev Fish Biol Fish 24:199-218

> Lal A, Arthur R, Marba N, Lill A, Alcoverro T (2010) Implications of conserving an ecosystem modifier: increasing green turtle (Chelonia mydas) densities substantially 
alters seagrass meadows. Biol Conserv 143:2730-2738

Lanyon JM, Limpus CJ, Marsh H (1989) Dugongs and turtles: grazers in the seagrass system. In: Larkum AWD, McComb AJ, Shepherd SA (eds) Biology of Australian seagrass: an Australian perspective. Elsevier, Amsterdam, p 610-634

Lecchini D, Planes S, Galzin R (2007) The influence of habitat characteristics and conspecifics on attraction and survival of coral reef fish juveniles. J Exp Mar Biol Ecol 341: 85-90

Lidgard DC, Bowen WD, Jonsen ID, Iverson SJ (2014) Predator-borne acoustic transceivers and GPS tracking reveal spatiotemporal patterns of encounters with acoustically tagged fish in the open ocean. Mar Ecol Prog Ser 501:157-168

Limpus CJ (1995) Global overview of the status of marine turtles: a 1995 viewpoint. In: Bjorndal KA (ed) Biology and conservation of sea turtles, 2nd edn. Smithsonian Institution Press, Washington, DC, p 605-610

Limpus CJ, Miller JD, Parmenter CJ, Reimer D, McLachlan N, Webb R (1992) Migration of green (Chelonia mydas) and loggerhead (Caretta caretta) turtles to and from eastern Australian rookeries. Aust Wildl Res 19:347-357

Moran KL, Bjorndal KA (2005) Simulated green turtles grazing affects structure and productivity of seagrass pastures. Mar Ecol Prog Ser 305:235-247

Morris DW (2003a) Toward an ecological synthesis: a case for habitat selection. Oecologia 136:1-3

Morris DW (2003b) How can we apply theories of habitat selection to wildlife conservation and management? Wildl Res 30:303-319

Mortimer JA, Portier KM (1989) Reproductive homing and interesting behaviour of the green turtle (Chelonia mydas) at Ascension Island, South Atlantic Ocean. Copeia 1989:962-977

NMFS SEFSC (National Marine Fisheries Service Southeast Fisheries Science Center) (2008) Sea turtle research techniques manual. NOAA Memo NMFS-SEFSC-579, Washington, DC

Orth RJ, Carruthers TJB, Dennison WC, Duarte CM and others (2006) A global crisis for seagrass ecosystems. Bioscience 56:987-996

> Pedersen MW, Weng KC (2013) Estimating individual animal movement from observation networks. Methods Ecol Evol 4:920-929

Plotkin PT (2003) Adult migrations and habitat use. In: Lutz PL, Musick JA, Wyneken J (eds) The biology of sea turtles, Vol II. CRC Press, Boca Raton, FL, p 225-241

Reardon RT (2000) Annual report - 2000 season. Dry Tortugas National Park Sea Turtle Monitoring Program, Dry Tortugas, FL

Rosenzweig ML (1991) Habitat selection and population interactions: the search for mechanism. Am Nat 137:S5-S28

Schofield G, Katselidis KA, Pantis JD, Dimopoulos P, Hays GC (2006) Behaviour analysis of the loggerhead sea turtle Caretta caretta from direct in-water observation. Endang Species Res 2:71-79

Schofield G, Katselidis KA, Pantis JD, Dimopoulos P, Hays GC (2007) Female-female aggression: structure of interaction and outcome in loggerhead sea turtles. Mar Ecol Prog Ser 336:267-274

Schofield G, Bishop CM, Katselidis KA, Dimopoulos P, Pantis JD, Hays GC (2009) Microhabitat selection by sea turtles in a dynamic thermal environment. J Anim Ecol $78: 14-21$

Editorial responsibility: Graeme Hays, Burwood, VIC, Australia
Schofield G, Hobson VJ, Fossette S, Lilley MKS, Katselidis KA, Hays GC (2010) Fidelity to foraging sites, consistency of migration routes and habitat modulation of home range on sea turtles. Divers Distrib 16:840-853

Seminoff JA, Resendiz A, Nichols WJ (2002) Home range of green turtles Chelonia mydas at a coastal foraging area in the Gulf of California, Mexico. Mar Ecol Prog Ser 242: 253-265

Senko J, Koch V, Megill WM, Carthy RR, Templeton RP, Nichols WJ (2010) Fine scale daily movements and habitat use of East Pacific green turtles at a shallow coastal lagoon in Baha California Sur, Mexico. J Exp Mar Biol Ecol 391:92-100

Shaver DJ, Hart KM, Fujisaki I, Rubio C, Sartain AR (2013) Movement mysteries: spatial ecology of juvenile green sea turtles. In: Lutterschmidt WI (ed) Reptiles in research: investigations of ecology, physiology, and behavior from desert to sea. Nova Science Publishers, Happauge, NY, p 463-484

Simpfendorfer CA, Heupel MR, Hueter RE (2002) Estimation of short-term centers of activity from an array of omnidirectional hydrophones and its use in studying animal movements. Can J Fish Aquat Sci 59:23-32

Spiegelhalter DJ, Best NG, Carlin BP, Van der Linde A (2002) Bayesian measures of model complexity and fit (with discussion). J R Stat Soc B 64:583-616

Spotila JR (2004) Sea turtles: a complete guide to their biology, behavior, and conservation, Johns Hopkins University Press, Baltimore, MD

Stamps A (1991) The effect of conspecifics on habitat selection in territorial species. Behav Ecol Sociobiol 28:29-36

Stokes KL, Broderick AC, Canbolat AF, Candan O and others (2015) Migratory corridors and foraging hotspots: critical habitats identified for Mediterranean green turtles. Divers Distrib 21:665-674

- Thayer GW, Bjorndal KA, Ogden JC, Williams SL, Zieman JC (1984) Role of larger herbivores in seagrass communities. Estuaries 7:351-376

Vander Zanden HB, Bjorndal KA, Reich KJ, Bolten AB (2010) Individual specialists in a generalist population: results from a long-term stable isotope series. Biol Lett 6: 711-714

- Vincent C, McConnell BJ, Ridoux V, Fedak MA (2002) Assessment of Argos location accuracy from satellite tags deployed on captive gray seals. Mar Mamm Sci 18: 156-166

Waara RJ (2011) Development and policy applications of the 2010 benthic habitat map for Dry Tortugas National Park. Natural Resource Technical Report NPS/SFCN/ NRTR-2011/474. National Park Service, Fort Collins, CO

> Wallace BP, DiMatteo AD, Hurley BJ, Finkbeiner EM and others (2010) Regional management units for marine turtles: a novel framework for prioritizing conservation and research across multiple scales. PLoS ONE 5:e15465

- Ward MP, Schlossberg S (2004) Conspecific attraction and conservation of territorial songbirds. Conserv Biol 18: 519-525

Witt MJ, Åkesson S, Broderick AC, Coyne MS and others (2010) Assessing accuracy and utility of satellite-tracking data using Argos-linked Fastloc-GPS. Anim Behav 80: 571-581

Zeh DR, Heupel MR, Limpus CJ, Hamann M, Fuentes MM, Babcock RC, Marsh H (2015) Is acoustic tracking appropriate for air-breathing marine animals? Dugongs as a case study. J Exp Mar Biol Ecol 464:1-10

Submitted: February 11, 2015; Accepted: December 22, 2015 Proofs received from author(s): February 5, 2016 